\title{
Cyclosporin A in steroid-sensitive nephrotic syndrome with frequent relapses
}

\author{
M.K. Chan and I.K.P. Cheng \\ Department of Medicine, University of Hong Kong, Queen Mary Hospital, Hong Kong
}

\begin{abstract}
Summary: Eight patients with steroid-sensitive nephrotic syndrome which frequently relapsed despite cyclosphosphamide treatment were given cyclosporin A $(7.5 \mathrm{mg} / \mathrm{kg} /$ day to $10 \mathrm{mg} / \mathrm{kg} /$ day $)$ for 8 to 12 weeks. Six had minimal change glomerulonephritis and two had focal segmental glomerulonephritis. Cyclosporin A was given to 5 patients when their nephrotic syndrome was in relapse and to 3 patients when the nephrotic syndrome was in remission. Cyclosporin $A$ induced a transient remission in only one patient.
\end{abstract}

\section{Introduction}

Minimal change glomerulonephritis produces a nephrotic syndrome which is responsive to treatment with corticosteroids. Relapses often occur when steroid is discontinued or reduced in dose. Cyclophosphamide has been used to prevent such relapses. Both prolonged steroid and cyclophosphamide treatment is associated with considerable morbidity. Cyclosporin A (CyA), a novel anti-T-lymphocyte immunosuppressive agent that has been used with great success in organ transplantation, has been tried in experimental glomerulonephritis.' We report our experience of using CyA in the treatment of the nephrotic syndrome which has frequently relapsed despite repeated steroid and cyclophosphamide therapy.

\section{Patients and methods}

Eight patients with a relapsing nephrotic syndrome were treated with CyA. Six had biopsy proven minimal change glomerulonephritis and 2 had focal segmental glomerulosclerosis (FSGS) (one diagnosed on initial biopsy and the other on repeat biopsy). Their age ranged from 23 to 40 years with a mean of 28 years. All patients with minimal change glomerulonephritis were males as was one patient with FSGS. The age at which the patients initially presented with the nephrotic syndrome varied from 13 to 34 years and the number of relapses varied from 2 to 17 episodes with a mean of 9.5 episodes in 81 months. All patients with minimal change showed good response to steroids initially. All except one patient had been treated with cyclophosphamide. CyA was given to all patients in a dose

Correspondence: M.K. Chan, M.D., F.R.C.P.(E), F.R.C.P. Accepted: 10 March 1987 varying from $7.5 \mathrm{mg} / \mathrm{kg}$ to $10 \mathrm{mg} / \mathrm{kg}$ daily in two divided doses for 8 to 12 weeks. The response to treatment was assessed in the conventional manner by clinical examination, determination of $24 \mathrm{~h}$ urinary protein excretion and renal function profiling which included serum albumin and cholesterol concentrations.

\section{Results}

In 5 patients (patients 1 to 5, Table I) CyA was given when the patients were nephrotic. In one patient the response was good. The nephrotic syndrome remitted in 4 weeks but relapsed 4 weeks after discontinuation of CyA. One patient, who had already suffered aseptic necrosis of the hips because of prolonged and repeated steroid therapy, showed a partial response. Proteinuria decreased but a full nephrotic syndrome recurred 14 weeks after CyA had been discontinued. One patient, who was given CyA in a dose of $7.5 \mathrm{mg} / \mathrm{kg}$ for 8 weeks, showed no signs of response to the treatment. His nephrotic syndrome remitted promptly when steroid was introduced again. The last patient in this group had FSGS on the first renal biopsy. She showed a partial response to a combination of cyclophosphamide and steroids. When the nephrotic syndrome recurred, she was given $7.5 \mathrm{mg} / \mathrm{kg}$ of CyA for 8 weeks. Her nephrotic syndrome did not improve; $250 \mathrm{mg} \mathrm{CyA}$ was then given by intravenous infusion daily for 5 days. She developed acute deterioration in renal function which improved when CyA treatment was withdrawn. There was no response in proteinuria.

Three patients (Patients 6-8, Table I) were given CyA when the nephrotic syndrome was in remission. In all, the nephrotic syndrome relapsed when $\mathrm{CyA}$ and 
Table I Use of cyclosporin A in steroid-sensitive nephrotic syndrome with frequent relapses

\begin{tabular}{|c|c|c|c|c|c|c|}
\hline Patient & $A g e^{*}$ & No. of relapses $\dagger$ & Cyclophosphamide $\ddagger$ & $\begin{array}{c}C y A \\
(m g / k g / d a y)\end{array}$ & Response & Side effect \\
\hline $1(\mathrm{~m})$ & $31(21)$ & $10(120 \mathrm{~m})$ & no & 7.5 (8 wks) & no & 个 creatinine \\
\hline $2(\mathrm{~m})$ & $40(34)$ & $13(66 \mathrm{~m})$ & yes $\times 3$ & 10 (8 wks) & yes & gum hypertrophy \\
\hline $3(\mathrm{f})$ & $33(31)$ & $2(18 \mathrm{~m})$ & yes $\times 2$ & 7.5 (8 wks) & no & $\uparrow$ creatinine \\
\hline $4(\mathrm{~m})$ & $25(23)$ & $5(20 \mathrm{~m})$ & yes $\times 1$ & 10 (8 wks) & partial & nil \\
\hline $5(\mathrm{~m})$ & $25(18)$ & $17(84 \mathrm{~m})$ & yes $\times 1$ & 10 (8wks) & no & hypertrichosis \\
\hline $6(\mathrm{~m})$ & $23(14)$ & $9(102 \mathrm{~m})$ & yes $\times 2$ & 10 (12 wks) & no & nil \\
\hline $7(\mathrm{~m})$ & $23(14)$ & $10(108 \mathrm{~m})$ & yes $\times 3$ & 10 (8 wks) & no & nil \\
\hline $8(\mathrm{~m})$ & 24 (13) & $10(132 \mathrm{~m})$ & yes $\times 2$ & 10 (12wks) & no & nil \\
\hline
\end{tabular}

*Number in parenthesis indicates age at first presentation; $\uparrow$ Number in parenthesis indicates time in months during which the relapses occur; $¥$ Cyclophosphamide treatment consisted of $100 \mathrm{mg} /$ day for 8 to 12 . weeks.

steroid treatment was completely withdrawn and remitted when steroid was reintroduced. Three patients showed noticeable gingival hyperplasia and one had hypertrichosis. Serum creatinine concentrations increased in two patients but returned to pre-treatment level after CyA had been discontinued.

\section{Discussion}

All our patients had a rather protracted relapsing nephrotic syndrome. Untoward side effects of steroid, for example, aseptic necrosis of the hips, and of cyclophosphamide, for example, reduced fertility, renders it desirable to search for a substitute for steroid and cyclophosphamide treatment. The pathogenesis of minimal change glomerulonephritis remains unsettled and many investigators regard FSGS as a variant of minimal change glomerulonephritis. ${ }^{2}$ Although cyclophosphamide has been reported to reduce relapses of nephrotic syndrome, all our patients had frequent relapses despite cyclophosphamide therapy. This, together with the suggestion that minimal change glomerulonephritis results from a T-cell defect, ${ }^{3,4}$ prompted us to use CyA in our patients in spite of the cost of the drug. CyA acts on T helper cells and reduces the production of lymphokines ${ }^{5}$ and therefore appears ideal for a condition thought to be mediated by lymphokines. ${ }^{3} \mathrm{CyA}$ has been shown to reduce IgE synthesis ${ }^{6}$ and patients with the nephrotic

\section{References}

1. Tipping, P.G. \& Holdsworth, S.R. Effect of cyclosporin $A$ on antibody induced experimental glomerulonephritis. Nephron 1985, 40: 201-205.

2. Habib, R., Churg, J., Bernstein, J. et al. Minimal change disease, mesangial proliferative glomerulonephritis and focal sclerosis: Individual entities or a spectrum of disease? In Robinson, R. (ed) Nephrology I. SpringerVerlag, New York 1984, pp 634-644. syndrome often have high IgE levels. ${ }^{7,8}$ Our preliminary experience is rather disappointing. Certainly when given alone to patients who were nephrotic, CyA induced a remission in only one out of 4 patients. The prompt response of the nephrotic syndrome to the reintroduction of steroids reflects the fact that $\mathrm{CyA}$ and steroids have distinctly different immunosuppressive properties. Although the follow-up after discontinuation of CyA was too short to make a firm conclusion that the 'frequency' of relapses cannot be reduced by $\mathrm{CyA}$, the fact that the nephrotic syndrome promptly recurred when CyA was withdrawn is rather discouraging. There was good compliance in oud patients. The mean trough plasma CyA leves. measured in 4 patients by radioimmunoassay was $200 \mathrm{ng} / 1$. To circumvent the possibility that $\mathrm{CyA}$ absorption might be impaired in the nephrotic state, we infused CyA intravenously in one patient without therapeutic effect despite nephrotoxicity. The dose of CyA we used $(7.5 \mathrm{mg} / \mathrm{kg}$ to $10 \mathrm{mg} / \mathrm{kg}$ ) was comparable to that used in organ transplantation, and the duration of treatment ( 8 to 12 weeks) should be long enough for a therapeutic effect to be observed. Nevertheless, used the way we did in steroid-sensitive nephrotic syndrome which relapses frequently despite cyclophosphamide treatment, $\mathrm{CyA}$ is disappointing at least in the short term, although others have reported more favourable results. ${ }^{9-12}$ It may be relevant that the nephrotic syndrome has recurred after renal transplantation despite continuous $\mathrm{CyA}$ treatment. ${ }^{13}$

3. Shalhoub, R.J. Pathogenesis of lipoid nephrosis: a disor- o der of T cell function. Lancet 1974, ii: 556-560.

4. Matsumoto, K., Osakabe, K., Harada, M. \& Hatano, M. Impaired cell-mediated immunity in lipoid nephrosis. Nephron 1981, 29: 190-194.

5. Ganelli-Piperno, A., Inaba, K. \& Steinman, R.M. Stimulation of lymphokine release from $\mathrm{T}$ lymphoblasts. Requirement for RNA synthesis and inhibition by 
cyclosporin A. J Exp Med 1984, 160: 1792-1802.

6. Okudaira, H., Sakurai, Y., Terada, K., Terada E, Ogita, T. \& Miyameto, T. Cyclosporin A-induced suppression of ongoing IgE antibody formation in the mouse. Int Arch Allergy Appl Immunol 1986, 79: 164-168.

7. Meadow, S.R. \& Sarsfield, J.K. Steroid-responsive nephrotic syndrome and allergy: clinical studies. Arch Dis Child 1981, 56: 509-616.

8. Chan, M.K., Chan, K.W. \& Jones, B. Immunoglobulins (IgG, IgA, IgM, IgE) and complement components (C3, C4) in nephrotic syndrome due to minimal change and other forms of glomerulonephritis, a clue for steroid therapy? Nephron 1987 (in press).

9. Capodicasa, G., De Santo, N.G., Nuzzi, F. \& Giordano, C. Cyclosporin A in nephrotic syndrome of child- hood: A 14 month experience. Int J Pediatr Nephrol 1986, 7: 69-72.

10. Meyrier, A., Simon, P., Perret, G. \& CondaminMeyrier, M.C. Remission of idiopathic nephrotic syndrome after treatment with cyclosporin A. Br Med J 1986, 292: 789-792.

11. Hoyer, P.F., Krull, F. \& Brodehl, J. Cyclosporin in frequently relapsing minimal change nephrotic syndrome. Lancet 1986, ii: 335.

12. Lagrue, G., Laurent, J., Belghiti, D. \& Robeva, R. Cyclosporin in idiopathic nephrotic syndrome. Lancet 1986, ii: 692-693.

13. Voets, A.J., Hoitsma, A.J. Koene, R.A. Recurrence of nephrotic syndrome during cyclosporin treatment after renal transplantation. Lancet 1986, i: 266-267. 